\title{
Assessment of genetic purity in rice (Oryza sativa L.) hybrids using microsatellite markers
}

\author{
Anjana Bora $^{1,2} \cdot$ Partha Ray Choudhury $^{1} \cdot$ Veena Pande $^{2} \cdot$ Asit B. Mandal $^{1}$
}

Received: 9 April 2015/ Accepted: 18 July 2015/Published online: 8 February 2016

(c) The Author(s) 2016. This article is published with open access at Springerlink.com

\begin{abstract}
The objective of the present study is to detect genetic impurity in the seed lots of CMS lines, restorers and hybrids and to identify signature markers to differentiate parents and hybrids through DNA-based assays. Furthermore, attempts have been made to find out an alternative to Grow-Out-Test, which is very tedious, time consuming and used conventionally for seed genetic purity testing since beginning of quality seed multiplication chain. Fifty-one rice-specific sequence tagged microsatellite (STMS) primer pairs distributed throughout the rice genome were employed for fingerprinting of eight rice hybrids and their parental lines with a view to assess variation within parental lines and to test the genetic purity of the commercial seed lots. Among those, 51 markers, 28 microsatellite markers showed polymorphism $(54.90 \%)$. A total of 98 alleles were obtained with an average of 1.92 alleles per primer pair and number of alleles amplified for each primer pair ranged from 1 to 4 . A set of markers were identified to differentiate parental lines of the hybrids and which emphasizes the immense scope of those molecular markers for their use in the unambiguous identification of hybrid, which would be of great benefit to farmers that depend on the hybrids.
\end{abstract}

Keywords Genetic purity - Grow-out-test - Hybrid rice · STMS

Asit B. Mandal

amandal2@rediffmail.com

1 Directorate of Seed Research, Indian Council of Agricultural Research, Mau 275101, Uttar Pradesh, India

2 Department of Biotechnology, Kumaun University, Bhimtal Campus, Nainital 263136, Uttarakhand, India

\section{Introduction}

Rice, Oryza sativa is one of the most important staple food crops in the world. About $90 \%$ of rice is grown and consumed in Asia. The food security of more than half the world population depends upon the ability of the world to produce and supply this life-line staple food crop for our survival, sustenance and perpetuation. It has been estimated that rice production in India as well as in several other Asian countries must be doubled by 2025 A.D to meet the emerging requirements of the booming up population (Hossain 1996; Paroda 1998). Further, very recently upon considering the global climate change, it has been projected that global food production needs to be increased by $70 \%$ by 2050 to meet the demand caused by increasing global population and thereby consumption (Varshney et al. 2011). India is considered to be leader in hybrid technology and has developed hybrids in as many as eight crops, which has boosted the productivity and production in several crops. Hybrids have a yield advantage of at least 15-20\% over high yielding inbred lines and gaining popularity in the farming community day by day being a productive input for more profitability. Hybrid technology has been exploited in many crops and poses major challenges in sustaining the benefits of hybrid technology by ensuring the genetic purity of the hybrid seeds supplied to the farmers, mostly by the private companies at very high cost. In a self-pollinated crop like rice, one of the major challenges is the production and supply of adequate quantities of pure inbred and hybrid seeds to the farmers for large-scale cultivation to augment production. It is estimated that for every $1 \%$ impurity in the hybrid seed, the yield reduction is $100 \mathrm{~kg}$ per hectare (Mao et al. 1996). Maintenance of high level of genetic purity of inbred, parental lines and hybrid is thereby inevitable and 
indispensable to harness the benefit of high heterosis, which is the key to bring success in hybrid husbandry of any economically important crop in the public domain.

The genetic purity during multiplication stages is prone to contamination due to the presence of pollen shedders as well as physical admixtures during processing. Genetic purity test is conventionally done to assess any deviation from genuineness of the variety during its multiplications and is a compulsion for seed certification of different categories of seeds though it is very much stringent for breeder seeds since it makes the foundation of seed multiplication chain. Unambiguous identification of crop varieties and hybrids is essential for their intellectual property right (IPR) protection, prevention of unauthorized commercial use and misuse of brand name by selling spurious seeds, etc., which are rampant in India inspite of 30 regulatory rules, laws and amendments in vouge.

The purity of hybrid seed is conventionally assayed by conducting Grow-Out-Test (GOT) involving representative sample of the seed to be marketed. A set of qualitative and quantitative characters known as "descriptors" stringently related to seed quality are currently used for varietal identification. Some of the characters, particularly those showing quantitative inheritance, interact with the environment and thus make the process of variety identification empirical and sometimes illusive due to masking effect of $\mathrm{G} \times \mathrm{E}$ interaction. Moreover, GOT is time consuming (takes one full growing season for completion), tedious and highly vulnerable to manpower abuse and infrastructure used. Molecular markers, in contrast, being based on DNA sequence variation, provide an unbiased means of identifying crop varieties. Among the various DNA-based markers currently available, the sequence tagged microsatellite (STMS) markers are most widely used for rapid genetic purity assessment of the hybrid and parental lines (Yashitola et al. 2002; Nandakumar et al. 2004; Antonova et al. 2006; Sundaram et al. 2008 and Pallavi et al. 2011). Microsatellite markers being co-dominant in nature are preferred as desirable markers (markers of choice) in rice besides their abundance and uniform distribution throughout the genome (Akagi et al. 1996; McCouch et al. 1997). Availability of more than 2740 mapped microsatellite markers with an average density of one STMS for every $157 \mathrm{~kb}(<1 \mathrm{~cm})$ of the rice genome (Cho et al. 2000; Temnykh et al. 2000; McCouch et al. 2002) has greatly improved their utility in genetic purity assessment.

The present study was undertaken to identify a set of STMS markers for fingerprinting of eight rice hybrids and their parental lines, which are being used in production en masse so that their genetic purity can be assessed and restored as well as the Sovereign right of the producers is protected by halting biopiracy. In addition, the utility of those markers was validated for the purpose of testing the genetic purity of the commercial seed lot.

\section{Materials and methods}

\section{Plant materials}

For the purpose of molecular identification, 8 public sector bred rice hybrids released for commercial cultivation in different parts of India in the public domain and their parental lines were obtained from rice collections maintained by rice breeders at different research institutes in India (Table 1). A random sample of 450 seeds, representing the commercial $\mathrm{F}_{1}$ seed lot was used for testing their genetic purity. Out of 450, 50 randomly drawn $F_{1}$ seeds of each of the hybrids was used for analysis using rice-specific microsatellite markers and others were used for Grow-out-test (GOT). The GOT was conducted at experimental plot of Directorate of Seed Research (ICAR), Mau, Uttar Pradesh during Kharif-2009 and Kharif-2010.

Table 1 Details of the hybrids and their parental lines used in the study

\begin{tabular}{llllll}
\hline S.No & Hybrid & Parentage & & Grain character \\
\cline { 3 - 5 } & & CMS line & Restorer line & \\
\hline 1 & PSD 1 & UPRI 95-17 A & UPRI 92-133 R & Slender, long & GBPUA and T \\
2 & PSD 3 & UPRI 95-17 A & UPRI 93-287 R & Slender, long & GBPUA and T \\
3 & CORH 3 & TNAUCMS 2A & CB 87 R & Slender, medium & PBS, TNAU \\
4 & DRRH 2 & IR 68897 A & DR 714-1-2R & Slender, long & DRR, Hyderabad \\
5 & Sahyadri & IR 58025 A & BR 827-35R & Slender, long & RARS, Karjat \\
6 & Sahyadri 2 & IR 58025 A & KJTR 2 & Slender, long & RARS, Karjat \\
7 & Sahyadri 3 & IR 58025 A & KJTR 3 & Slender, long & RARS, Karjat \\
8 & Sahyadri 4 & IR 58025 A & KJTR 4 & Slender, long & RARS, Karjat \\
\hline
\end{tabular}

GBPUA and T Govind Ballabh Pant University of Agriculture and Technology, Uttarakhand, PBS Paddy Breeding Station, TNAU, Coimbatore, Tamil Nadu, DRR Directorate of Rice Research, Rajendranagar, Hyderabad, RARS Regional Agricultural Research Station, Karjat, Maharashtra 


\section{Molecular analysis}

The genomic DNA was isolated from bulked leaf samples from 5 lots each containing 10 young seedlings following CetylTrimethyl Ammonium Bromide (CTAB) method (Murray and Thompson 1980). Quantification of DNA was done by analyzing the purified DNA on $0.8 \%$ agarose gel using dilute uncut lambda DNA ( $400 \mu \mathrm{g} / \mathrm{mL}$, Bangalore Genei Pvt. Ltd., Bangalore, India) as standard and also spectrophotometrically. The average value was used to calculate the DNA concentration. DNA was diluted in $\mathrm{T}_{10} \mathrm{E}_{1}$ to a concentration of about $12.5 \mathrm{ng} / \mu \mathrm{L}$ for PCR analysis. The sequence information for the primer pairs was obtained from the publications of $\mathrm{Wu}$ and Tanksley (1993), Chen et al. (1997) and Temnykh et al. (2000) and synthesized from GCC Biotech Pvt. Ltd., India.

\section{PCR amplification}

Fifty-one STMS primer pairs (custom synthesized oligo nucleotide sequence) were selected for this study. DNA amplification was carried out in a $25 \mu \mathrm{L}$ reaction mixture containing 1X PCR assay buffer $(50 \mathrm{mM} \mathrm{KCl}, 10 \mathrm{mM}$ Tris-Cl, $1.5 \mathrm{mM} \mathrm{MgCl} 2$ ), $200 \mu \mathrm{M}$ each of dNTPs, $0.2 \mu \mathrm{M}$ each of forward and reverse primers, 0.6 units of Taq DNA polymerase (Bangalore Genei Pvt. Ltd., Bangalore, India) and $25 \mathrm{ng}$ of genomic DNA template. The amplification reaction was carried out in a thermal cycler (Eppendorf AG 22331, Hamburg, Germany). The first cycle consisted of denaturation of template DNA at $94{ }^{\circ} \mathrm{C}$ for $5 \mathrm{~min}$, primer annealing $\left(55^{\circ} \mathrm{C}\right)$ for $1 \mathrm{~min}$ and primer extension $\left(72^{\circ} \mathrm{C}\right)$ for $2 \mathrm{~min}$. In the next 33 cycles, the period of denaturation was reduced to $1 \mathrm{~min}$ while the primer annealing and primer extension time kept same as in the first cycle. The last cycle consisted of only primer extension $\left(72^{\circ} \mathrm{C}\right)$ for $7 \mathrm{~min}$.

The amplified products were separated by electrophoresis in $3 \%$ Metaphor $^{\mathrm{TM}}$ agarose (Lonza, USA) gel containing $1 \mathrm{mg} /$ $\mathrm{ml}$ ethidium bromide. The size of the amplified fragments was determined using size standards (Low range DNA ladder, MBI Fermentas, Lithuania). DNA fragments were visualized under UV light in a gel documentation system (Bio-Rad, USA). The markers displayed distinct amplification of specific allele combination in hybrids and parental lines and were considered as informative SSR markers. The impurities were detected based on deviation in the expected amplification pattern.

\section{Results}

\section{Assessment of genetic purity through fingerprinting of rice hybrids and their parental lines}

The 8 rice hybrids and their parental lines were analyzed using 51 rice-specific microsatellite markers for fingerprinting and to identify genetic impurities in the seed lot of CMS lines, restorers and hybrids. A total of 98 alleles were obtained using 51 markers with an average of 1.92 alleles per primer pair. The number of alleles amplified for each primer pair ranged from 1 to 4 . The markers RM 154, RM 108 and RM 145 amplified a maximum of four alleles, while 13 STMS markers (RM 341, RM 337, RM 336, RM 144, RM 82, RM 7324, RM 177, RM 124, RM 169, RM 192, RM 3399, RM 3589, and RM 104) amplified three alleles each. Two alleles were amplified by a set of 12 markers (RM 186, RM 174, RM 269, RM 274, RM 6425, RM 297, RM 350, RM 101, RM 6881, RM 3530, RM 331, and RM 264) and rest of the 23 markers showed monomorphic (single) allelic pattern.

This study identified a set of seven STMS markers (RM 336, RM 337, RM 154, RM 331, RM 341, RM 297, and RM 3399), which could identify and produce unique fingerprints for all the eight rice hybrids and therefore must be considered as highly informative and may be used as molecular tags or referral markers in preparing "Molecular ID Cards" for unambiguous identification of the hybrids and their parents under reference (Table 2; Fig. 1). It was also observed that RM 101 was able to differentiate both the parents and hybrids of all the eight genotypes (hybrids and parental lines) used in the present study wherein male (300 bp), female (350 bp) and hybrid (both the amplicons) specific uniform banding pattern was obtained across the genotypes.

\section{Testing genetic purity of hybrid seeds}

Characterization and identification of varieties/cultivars/genetic stocks or hybrids are crucial in any genetic improvement programme for their release in public domain and subsequent quality seed production for remunerative agriculture in the days to come. To obtain the best quality $F_{1}$ seed in the hybrid seed production programme, high genetic and physical purity in the seeds of the parental lines are pre-requisite. Assessment of genetic purity of hybrids and their parental lines is therefore utmost important to capitalize the benefit of heterosis in any economically important crop for our better survival and prosperity.

To test the genetic purity of the hybrids under study, in a random sample of 50 seeds, the marker RM 331 was found to identify an off-type in Sahyadri 2 rice hybrid (Fig. 2). This amounts to $2 \%$ off-types in the total hybrid seed produced. The results were confirmed using 400 seeds from the same seed lot through Grow-Out-Test (GOT) in the field.

\section{Field performance of the rice hybrid individuals}

As expected, comparative assessment of both data gleaned from the experiment involving SSR markers and GOT analyses was found to be similar vis-a-vis comparable. In the 
Table 2 SSR markers identified to be specific for the rice hybrids under study

\begin{tabular}{|c|c|c|c|c|c|}
\hline \multicolumn{6}{|l|}{ Size of allele (bp) } \\
\hline Hybrid & SSR marker & CL & Primer sequence $(\mathrm{F} / \mathrm{R})$ & CMS line & Restorer line \\
\hline \multirow[t]{2}{*}{ Pant Sankar Dhan 1} & RM 154 & 2 & ACCCTCTCCGCCTCGCCTCCTC & 170 & 210 \\
\hline & & & СТССТССТССТGCGACCGCTCC & & \\
\hline \multirow[t]{5}{*}{ Pant Sankar Dhan 3} & RM 336 & 7 & CTTACAGAGAAACGGCATCG & 190 & 150 \\
\hline & & & GCTGGTTTGTTTCAGGTTCG & & \\
\hline & RM 337 & 8 & GTAGGAAAGGAAGGGCAGAG & 500 & 150 \\
\hline & & & CGATAGATAGCTAGATGTGGCC & & \\
\hline & RM 154 & - & & 170 & 190 \\
\hline \multirow[t]{2}{*}{ CORH 3} & RM 341 & 2 & CAAGAAACCTCAATCCGAGC & 170 & 170,130 \\
\hline & & & CTCCTCCCGATCCCAATC & & \\
\hline \multirow[t]{2}{*}{ DRRH2 } & RM 336 & - & & 190 & 170 \\
\hline & RM 337 & - & & 200 & 500 \\
\hline \multirow[t]{2}{*}{ Sahyadri } & RM 297 & 1 & TCTTTGGAGGCGAGCTGAG & 190 & 230 \\
\hline & & & CGAAGGGTACATCTGCTTAG & & \\
\hline \multirow[t]{2}{*}{ Sahyadri 2} & RM 3399 & 4 & GACGCTTCTCAACGCCAC & 175,400 & $175,400,900$ \\
\hline & & & тСТССТСССТСССТСТTGTC & & \\
\hline Sahyadri 3 & RM 154 & - & & 160 & 190 \\
\hline \multirow[t]{2}{*}{ Sahyadri 4} & RM 331 & 8 & GAACCAGAGGACAAAAATGC & 210 & 160 \\
\hline & & & CATCATACATTTGCAGCCAG & & \\
\hline
\end{tabular}

$C L$ Chromosome location, $F$ Forward primer sequence (top), $R$ Reverse primer sequence (bottom)

Grow-out trials, purity evaluation was conducted based on morphological characters including plant height and days to maturity, pollen sterility, presence of awns on the spikelets, panicle exertion, panicle length, nodal pigmentation and flag leaf senescence. The characters of few individuals that had shown deviations in Sahyadri 2 from the standard set of characters were identified as off-type and which were also further supported by the molecular marker testing.

Except Sahyadri 2, no off-type was obtained in any of the hybrids which prospects immense scope of molecular markers in genetic purity test and could be easily comparable to GOT data. In case of Sahyadri 2, however, 1/50 of the individual hybrid (2\%) was found to be off-type using molecular data. When GOT data of 400 seeds of Sahyadri 2 grown in the field were analyzed for comparison, 6 out of $400(1.5 \%)$ plants were detected as off-types indicating that molecular data could perform and detect off-types better than that of morphological observations. This opens a new vistas that in future the tedious painstaking and lengthy GOT test would be replaced by more precise, easy to perform genetic purity test involving molecular marker precisely with ease and confidence.

\section{Discussions}

Determining genetic purity of the hybrids is one of the most important characteristics of good quality seed and is an essential requirement before it is sold commercially for cultivation in the field for more productivity as well as production. It is to be mentioned that there is a chance of contamination of the hybrid seed production plot through various means. Physical mixtures during the subsequent handling of the harvested materials (especially during threshing, drying, cleaning, grading, bagging) also facilitate contamination. The maintenance of high level of genetic purity of hybrid seeds is thus imperative to exploit heterosis, which is conventionally assayed by Grow-OutTest (GOT) involving representative sample of quality seed before marketing. The GOT is essentially based on morphological (phenotypic) uniformity. The procedure is highly empirical or subjective and largely depends upon as the expression of these traits. Such qualitative and quantitative traits are greatly influenced by the environmental factors. In addition, locking up of the venture capital invested on hybrid seed production and additional expenditure incurred on storage of hybrid seed ultimately increases the hybrid seed cost. With the advent of molecular markers, these limitations of morphological markers were found to be averted confidently. The stability of microsatellite/SSR markers over different environments, do not change. Furthermore, plant stage specificity and characteristics like reproducibility, multi-allelic nature, codominant inheritance, relative abundance and good genome coverage (Powell et al.1996) make microsatellite markers a very convenient and a marker of choice for testing distinctness of varieties through assessment of genetic purity 
Fig. 1 Polymorphism profile between parental lines and hybrids in rice involving microsatellite markers (the 7 selected primer pairs are represented; each lane contained bulked DNA of 10 seedlings of hybrids and their corresponding parental lines used as templates, details provided in Table 2; M: Low Range DNA Ladder, MBI Fermentas, Lithuania)

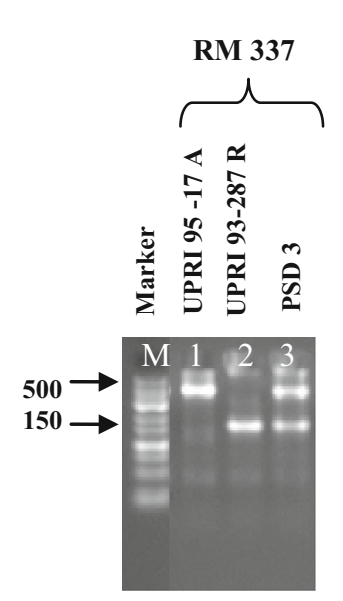

A

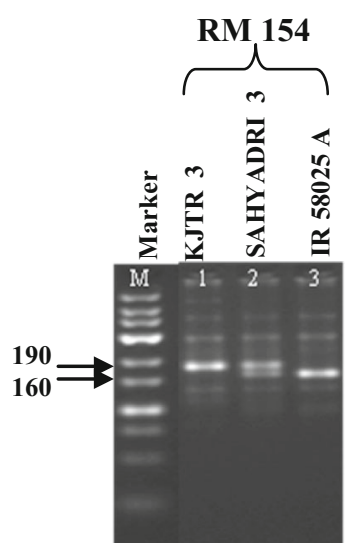

D

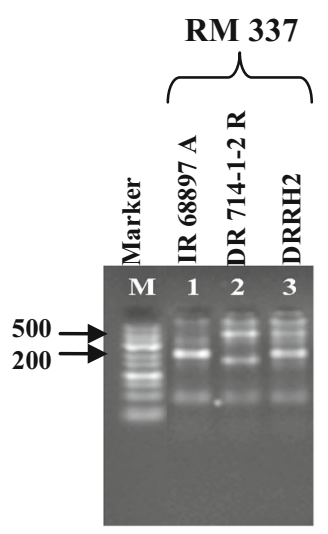

G

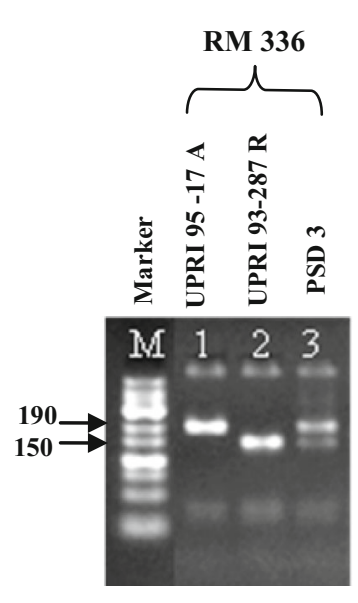

B

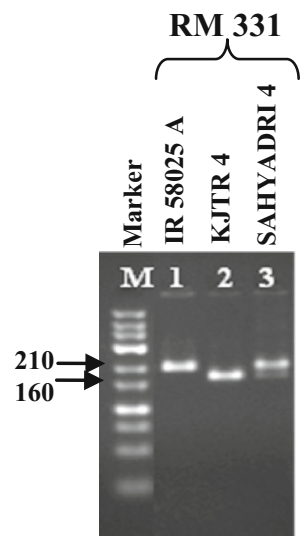

$\mathbf{E}$
RM 154

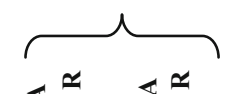

【一ำ

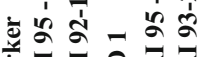

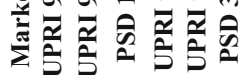

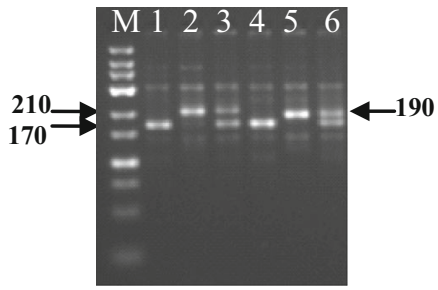

C

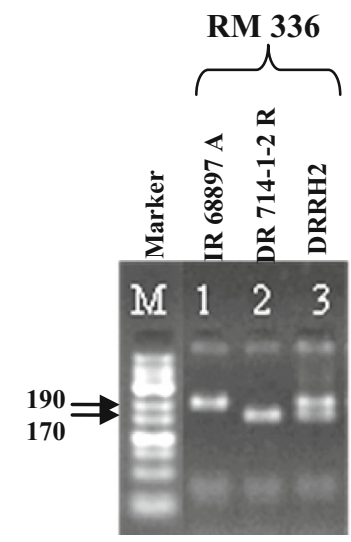

$\mathbf{F}$

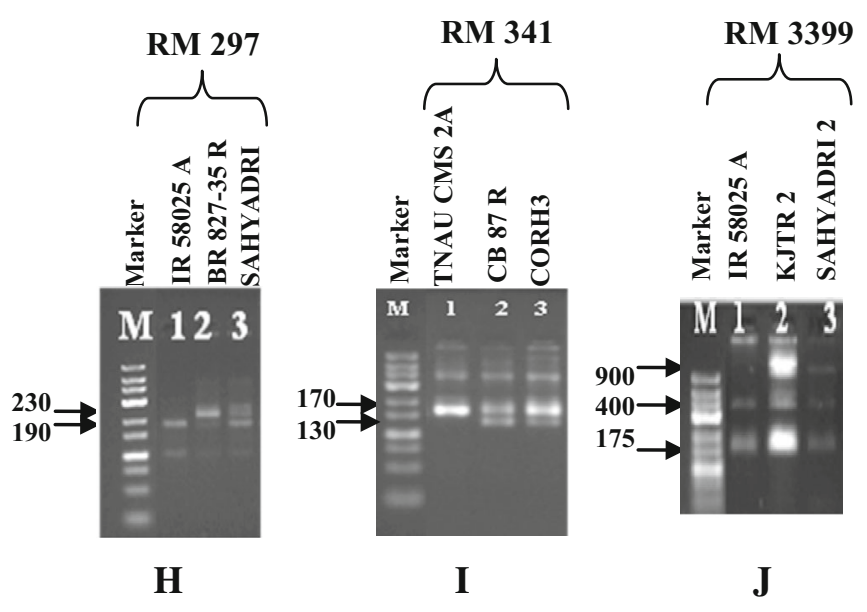

in the form of distinct amplicons profile, for future protection (Law et al. 1998) and for assessing genetic purity, specifically in high quality rice inbreds and hybrids. The use of STMS markers in hybrid rice seed purity analyses has been demonstrated earlier by many researchers. Nandakumar et al. (2004) employed 10 STMS markers for

fingerprinting 11 public sector bred rice hybrids and their parental lines and tested the genetic purity of the commercial seed lot. Sundaram et al. (2008) characterized 10 each of cytoplasmic male sterile (CMS) and restorer (R) lines along with 10 popular Indian rice varieties using a set of 48 SSR markers and marker combinations, those 


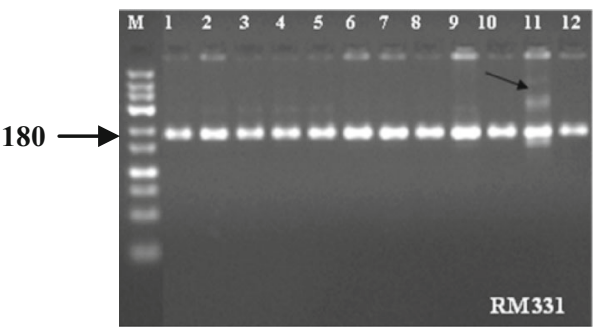

Fig. 2 Genetic purity testing of Sahyadri 2 hybrid seeds using the STMS marker RM 331. $\mathrm{M}=$ Low range DNA ladder, Lane $1=$ CMS line; Lane $2=$ Restorer line and Lane $3-12=$ individual F1 plants representing a random sample from hybrid seed lot of Sahyadri 2. Lane 11 (arrow) represents the off-type/contaminant

were found unique to a particular parental line or hybrid were also identified. Likewise, rice hybrid $\mathrm{CORH} 3$ was identified by RM 234 (Tamilkumar et al. 2009).

In our present study, we have observed the similar banding pattern for the parental lines and hybrid of DRRH2 using RM 336 as done by Sudharani et al. (2013), which confirms the reproducibility and appropriate compatibility/suitability of microsatellites as a marker to identify hybrids and their parental lines. Similar studies have also been done by (Kumar 2012) wherein the rice hybrid DDRH 2 was identified by microsatellite markers viz. RM 204, RM 234 and RM 228.

An attempt was made in our present investigation to identify rice hybrids and their respective parents and assess genetic purity of rice hybrids using microsatellite polymorphisms. The 8 rice hybrids studied here, have been released for commercial cultivation in diverse geographical locations across India and therefore, the molecular fingerprinting of these hybrids and their parental lines warrants utmost importance for protecting the Plant Breeders' Rights (PBR) and to halt biopiracy which is rampant in India and adjoining rice growing countries. Fifty-one STMS primer pairs selected for the study amplified a total of 98 alleles ranging from 1 to 4 alleles per primer pair with an average of 1.92 was obtained as against Tamilkumar et al. (2009) wherein 2-4 alleles per primer pair with an average of 2.9 alleles using 11 primer pairs were obtained, thus the result is comparable with the present study.

All the eight 8 rice hybrids could be precisely distinguished by the seven polymorphic STMS markers (RM 154, RM 336, RM 337, RM 341, RM 297, RM 331, and RM 3399) and unique DNA fingerprints with unique amplicons generated by those primers could be used as a set of referral STMS markers for identification of these hybrids. Therefore, it is concluded that genetic purity analysis using STMS marker may be used as a potential tool for resolving the problems arise in seed certification program owing to genetic impurity as well as the rapid determination of genetic purity of rice hybrids with the deployment of molecular makers as compared to GOT.

In a nutshell it can be concluded that use of precise DNA-based markers would perhaps replace GOT in the days to come, which is obviously very tedious, time consuming and highly vulnerable to manual mistakes that normally occur during production, processing and marketing.

Acknowledgments The authors are thankful to the Project Director, Directorate of Seed Research (Indian Council of Agricultural Research) for facilities provided.

\section{Compliance with ethical standards}

Conflict of interest We declare that we have no conflict of interest.

Open Access This article is distributed under the terms of the Creative Commons Attribution 4.0 International License (http:// creativecommons.org/licenses/by/4.0/), which permits unrestricted use, distribution, and reproduction in any medium, provided you give appropriate credit to the original author(s) and the source, provide a link to the Creative Commons license, and indicate if changes were made.

\section{References}

Akagi H, Yokozeki Y, Inagaki A, Fujimura T (1996) Microsatellite DNA markers for rice chromosomes. Theor Appl Genet 93:1071-1077

Antonova TS, Guchetl SZ, Tchelustnikova TA, Ramasanova SA (2006) Development of marker system for identification and certification of rice lines and hybrids on the basis of SSRanalysis. Helia 29:63-72

Chen X, Temnykh S, Xu Y, Cho YG, McCouch SR (1997) Development of a microsatellite framework map providing genomewide coverage in rice (Oryza sativa L.). Theor Appl Genet 95:553-567

Cho YG, Ishii T, Temnykh S, Chen X, Lipovich L, McCouch SR, Park WD, Ayres N, Cartinhour S (2000) Diversity of microsatellites derived from genomic libraries and Gen-Bank sequences in rice (Oryza sativa L.). Theor Appl Genet 100:713-722

Hossain M (1996) Economic prosperity in Asia: implications for rice research. In: Khush GS (ed) Rice Genetics III, Proceedings of the Third International Rice Genetics Symposium, Los Baños, Manila, 16-20 Oct 1995. International Rice Research Institute, Philippines, pp 3-16

Kumar MC (2012) Utilization of SSR Markers for Seed Purity Testing in Popular Rice Hybrids (Oryza sativa L.). Ann Plant Sci $1: 1-5$

Law JR, Donini P, Koebner RMD, Reeves JC, Cooke RJ (1998) DNA profiling and plant variety registration. III: the statistical assessment of distinctness in wheat using amplified fragment length polymorphisms. Euphytica 102:335-342

Mao CX, Virmani SS, Kumar I (1996) Technological innovations to lower the cost of hybrid rice seed production. In: Advance in hybrid rice technology. Proceedings of Third International Symposium on Hybrid Rice, Directorate of Rice Research, Hyderabad, India)

McCouch SR, Chen X, Panaud O, Temnykh S, Xu Y, Cho YG, Huang N, Ishii T, Blair M (1997) Microsatellite marker development, 
mapping and applications in rice genetics and breeding. Plant Mol Biol 35:89-99

McCouch SR, Teytelman L, Xu Y, Lobos KB, Clare K, Walton M, Fu B, Maghirang R, Li Z, Xing Y, Zhang Q, Kono I, Yano M, Fjellstrom R, DeClerck G, Schneider D, Cartinhour S, Ware D, Stein L (2002) Development and mapping of 2240 new SSR markers for rice (Oryza sativa L.). DNA Res 9:199-207

Murray MG, Thompson WF (1980) Rapid isolation of molecular weight plant DNA. Nucleic Acids Res 8:4321-4325

Nandakumar N, Singh AK, Sharma RK, Mohapatra T, Prabhu KV, Zaman FU (2004) Molecular fingerprinting of hybrids and assessment of genetic purity of hybrid seeds in rice using microsatellite markers. Euphytica 136:257-264

Pallavi HM, Gowda Rame, Shadakshari YG, Bhanuprakash K, Vishwanath K (2011) Identification of SSR markers for hybridity and seed genetic purity testing in sunflower (Helianthus annuus L.). Helia 34:59-66

Paroda RS (1998) Priorities and opportunities of rice production and consumption in India for self sufficiency. In: Sustainability of rice in the global food system, (ed.) Dowling NG, Greenfield, Fisher KS, Los Baños, Philippines: Pacific Basin Study Center, International Rice Research Institute, Manila, Philippines p357-390

Powell W, Morgante M, Andre C, Hanafey M, Vogel J, Tingey S, Rafalski A (1996) A comparison of RFLP, RAPD, AFLP and SSR (microsatellite) markers for germplasm analysis. Mol Breed 2:225-238
Sudharani M, RajyaLakshmi K, Vishnuvardhan AR, Bharthi K, RamaRaju N (2013) Use of DNA polymorphism for characterization and assessment of genetic purity testing in rice hybrids (Oryza sativa L.). Electron J Plant Breed 2:1113-1118

Sundaram RM, Naveenkumar B, Biradar SK, Balachandran SM, Mishra B, Ilyas Ahmed M, Viraktamath BC, Ramesha MS, Sarma NP (2008) Identification of informative SSR markers capable of distinguishing hybrid rice parental lines and their utilization in seed purity assessment. Euphytica 163:215-224

Tamilkumar P, Jerlin R, Senthil N, Ganeshan KN, Jeevan RJ, Raveendran M (2009) Fingerprinting of rice hybrids and their parental lines using microsatellite markers and their utilization in genetic purity assessment of hybrid rice. Res J Seed Sci 3:40-47

Temnykh S, Park WD, Ayres N, Cartinhour S, Hauck N, Lipovich L, Cho YG, Ishii T, McCouch SR (2000) Mapping and genome organization of microsatellite sequences in rice (Oryza sativa L.). Theor Appl Genet 100:697-712

Varshney RK, Bansal KC, Agarwal PK, Datta SK, Craufurd PQ (2011) Agricultural biotechnology for crop improvement in variable climate: hope or hype? Trends Plant Sci 16:363-371

Wu KS, Tanksley SD (1993) Abundance, polymorphism and genetic mapping of microsatellites in rice. Mol Gen Genet 241:225-235

Yashitola J, Thirumurugan T, Sundaram RM, Naseerullah MK, Ramesha MS, Sarma NP, Stone RV (2002) Assessment of purity of rice hybrids using microsatellite and STS markers. Crop Sci 42:1369-1373 